\title{
From Discourse to "Odd Coordinations" - On Asymmetric Coordination and Subject Gaps in German
}

\author{
Ingo Reich
}

\begin{abstract}
SLF-Coordination (SLFC) and Asymmetric Coordination (AC) in the sense of Höhle (1983, 1990) exhibit specific semantic (a 'fusing' interpretation) and syntactic properties (e.g., verb fronting in non-initial conjuncts). This paper ties together these characteristics by considering them an immediate consequence of the fact that in AC and SLFC properties typically attributed to 'coordinate' structures in discourse show up in 'grammaticalized' form. As far as the analysis of SLFC is concerned, it is furthermore argued that the dropping of the the subject (and only the subject) is in a sense parasitic on the special fusing semantics of the construction. That dropping the subject systematically results in an overt V1-structure is traced back to the way covert operators are licensed and identified in specifier positions in German (paralleling Topic Drop).
\end{abstract}

\section{Introduction}

German (like some other Germanic languages, for example, Dutch) exhibits an interesting, and at the same time recalcitrant construction, which we can describe somewhat sloppily as "subject gaps in coordinate structures" (SLFC). ${ }^{1}$ As it turns out, SLFC is closely related to yet another kind of 'non-standard' coordination observable in German (see Höhle, 1990): so-called "Asymmetric Coordination" (AC). While previous approaches to SLFC and AC have focused almost exclusively on their syntactic side (Reis, 1993, and Frank, 2002, being notable exceptions), this paper takes as its starting point the constructions' semantic and pragmatic peculiarities, and seeks to pull these together with their more formal characteristics. I will argue that properties typically attributed to coordination in discourse show up in AC and SLFC in 'grammaticalized' form, and thus determine both the constructions' specific semantic and syntactic

\footnotetext{
* I'd like to thank Veronika Ehrich, Cathrine Fabricius-Hansen, Angelika Kratzer, Claudia Maienborn, Jürgen Pafel, Wiebke Ramm, Marga Reis, Arnim von Stechow, Wolfgang Sternefeld, Hubert Truckenbrodt, Angelika Wöllstein and three anonymous referees for helpful comments and related discussion. Thanks to Kirsten Brock for checking my English.

${ }^{1}$ The term "SLF-coordination" is due to Höhle (1990) and is shorthand for "Subject Lacking in F-structure," where "F-structure" in turn stands for "Fronted structure," a technical term that refers to sentences which show overt verb fronting; see Höhle (1986) for details.
}

To appear in: C. Fabricius-Hansen \& W. Ramm (eds.), 'Subordination' vs. 'Coordination' in Sentence and Text. Amsterdam, Philadelphia: Benjamins. 
properties (among other things, verb fronting in non-initial conjuncts). Before laying out the details of my proposal, however, let me first introduce these characteristics of SLFC and AC, characteristics that in particular delineate this construction from what we may call 'standard' (symmetric) coordination.

\subsection{Subject Gaps in Coordinated Structures}

With this aim in view, consider the particularly interesting example (1), taken from a German online newspaper. Following Höhle (1983) SLFC can be characterized by three distinct properties: (i) Within non-initial conjuncts the finite verb is fronted; see tut ('pretends') in (1). (ii) Even though property (i) tells us that SLFC is most likely some case of sentential coordination (verb fronting requires a left periphery), the non-initial conjunct lacks a subject. ${ }^{2}$

(1) da stellt sich jemand vor die Mikrofone und there stands REFL somebody in front of the microphone and tut so, [als könne er etwas erklären] pretends PART, [as if could he something explain] 'Somebody stands there in front of the microphone, and pretends to be able to explain something'

(zeit.de, 26 January 2006)

But it is property (iii) that distinguishes SLFC from phrasal C'-coordinations like the one in (3), and which establishes SLFC as a separate phenomenon: Whereas in the case of (3) the subject jemand ('somebody') — which fills the 'shared' prefield ("Vorfeld") position left adjacent to the position of the fronted finite predicate - c-commands (and, thus, binds) the base positions $t_{1}$ of the fronted subject in both conjuncts, this is not the case with SLFC; see (2).

(2) da [[stellt sich jemand vor die Mikrofone] und [tut $S L$ so, ...]]

(3) jemand $_{1}\left[\left[\right.\right.$ stellt $t_{1}$ sich da vor die Mikrofone $]$ und [tut $t_{1}$ so, ...]]

In (2) the subject jemand of the first conjunct is located after [!] the fronted finite predicate stellt ('stands'), i.e., within the middle field ("Mittelfeld") of the first sentence. ${ }^{3}$ If we now try to analyze (2) along the lines of (3), we need to assume that (2) - like (3) - is a symmetrically coordinated V1-structure sharing a common prefield filled with $d a$ ('there'). This time, however, the subject of the first sentence does not c-command the base position $S L$ of the

${ }^{2}$ In a recent paper, Fortmann (2005) argues that it is not the subject per se, but in fact the highest argument of the verb (which is not necessarily the subject in German) that is dropped in SLFC; see, however, Reich (2007a) for critical discussion and a rejection of this position.

${ }^{3}$ This is, of course, one of the reasons why in subject-initial languages like, for example, English SLFC seems not to exist: the only syntactic structures in English that comply with property (iii) are inverted structures as used in English interrogatives. 
'dropped' subject in the second conjunct, which means that we cannot construe the subject gap $S L$ in (2) as a trace that is bound by the subject of the first sentence; that is, given phrasal C'-coordination, there is - in contrast to (3) no "across the board (ATB) movement" (Williams, 1978) analysis available.

There is one alternative, though, that we have to take into consideration here. If we suppose that examples like (3) are not the result of C'-coordination followed by ATB-movement, but that they are the result of CP-coordination followed by deletion of the subject, then we might still put forward a uniform analysis in terms of ellipsis (see, e.g., Wilder, 1997): Both structures could be taken to display instances of so-called "forward deletion," an ellipsis process deleting strings at the left periphery of non-initial conjuncts under identity. In the case of (2) and (3) this amounts to saying that (i) the subjects in non-initial conjuncts are to be located in the prefield, and (ii) that they are deleted in this position under identity with the subject in the first conjunct; see (4) and (5).

(4) [[da stellt sich jemand vor die Mikrofone] und [jemand tut ...]]

(5) [[jemand stellt sich da vor die Mikrofone] und [jemand tut ...]]

There is good evidence, however, that the lack of the subject in (1) cannot be due to "forward deletion" or some similar kind of deletion process. In fact, it is all but clear whether such a deletion process exists at all (see, e.g., Höhle, 1991; Hartmann, 2002). If it does, it certainly does not behave in crucial respects the way clear cases of ellipsis in coordinate structures do.

To see this, contrast the interpretation of elided indefinites in Gapping see (6) below - with the interpretation of elided indefinites in structures like (4) and (5) above. Whereas in the case of Gapping the interpretation of the indefinite etwas ('something') remains constant irrespective of whether etwas is realized overtly or covertly - in both cases, etwas in the second conjunct refers (in its preferred reading) to a different object than etwas in the first conjunctthis is not true of (4) and (5) above: In (4) and (5), it is claimed that there is one person who both stands in front of the microphone and who pretends to be able to explain something, i.e., the elided indefinite jemand is systematically interpreted as being 'coreferent' with its antecedent. Their overt counterparts in (7) and (8), however, are far more liberal: they may be, and in fact are taken as attributing the properties of standing in front of the microphone and of pretending to be able to explain something to two different persons.

(6) Peter schenkte Anna etwas und Anna schenktePeter etwas Petergave Anna s'thingand Annagave Peters'thing 'Peter gave Anna something, and Anna Peter'

(7) da stellt sich jemand vor die Mikrofone und jemand tut so, ... (8) jemand stellt sich da vor die Mikrofone und jemand tut so, ... 
Apart from this, "forward deletion" is subject to another important formal restriction not mentioned yet: It is not only the target of deletion that has to be positioned at the left periphery of its conjunct, but also its antecedent (see, e.g., van Oirsouw, 1993). This, however, immediately contradicts defining property (iii) of SLFC; and somewhat loosening that restriction would obviously lead to considerable overgeneration. Now, since the lack of the subject in non-initial conjuncts in SLFC seems to be due neither to ellipsis nor to ATB-movement, this property of SLFC remains - for the time being - quite puzzling.

\subsection{Asymmetric Coordination}

As Höhle (1990) observes, SLFC seems not to be restricted in its use to root clause phenomena like (1) above, but also occurs in dependent contexts as, for example, in the antecedent of a conditional; see (9).

(9) Wenn du nach Hause kommst und siehstden Gerichtsvollzieher if you back home come and see the bailiff vor der Tür, dann [...]

at the door, then [...]

'If you come home, and you see the bailiff at the door, then [...]'

Since SLFC requires fronting of the finite verb in non-initial conjuncts, we encounter, however, an unexpected word order asymmetry: While the finite verb is fronted in the second conjunct (overt V1-position), it is - because of the complementizer wenn ('if') - in final position (VE) in the first conjunct. This kind of word order asymmetry is in fact more general and is also found in coordinations that do not lack a subject in the second conjunct; see (10).

(10) Wenn du nach Hause kommst und der Gerichtsvollzieher if you back home come and the bailiff steht vor der Tür, dann [...]

stands at the door, then [...]

'If you come home, and the b. is standing at the door, then [...]'

Coordinations that show this kind of word order asymmetry have been dubbed "Asymmetric Coordination (AC)" — in a narrower sense - in Höhle (1990). As it turns out, SLFC and AC share many crucial properties (see Reich, 2007a, for detailed discussion), the two most prominent probably being (i) verb fronting, see (11a), and (ii) a fusing interpretation, see (11b).

\section{(11) a. VERB FRONTING}

In non-initial conjuncts the finite verb is fronted. 


\section{b. FUSING SEMANTICS}

SLFC and AC are subject to a 'one-event' interpretation.

That $\mathrm{AC}$ as well as SLFC do in fact require fronting of the finite predicate in non-initial conjuncts is easily illustrated by the following pair of examples:

(12) a. *Kommst du nach Hause und der GV vor der Tür steht, [...]

b. *Da stellt sich jemand vor die Mikrofone und so tut, [...]

The fact that AC and SLFC are subject to some kind of one-event interpretation is somewhat harder to illustrate. Höhle $(1983,22)$ gives the contrast in (13).

(13) a. Stehen da wieder welcherum und verteilen Flugblätter? stand there again folks around and hand out flyers? 'Are, again, folks standing around and handing out flyers?'

b. Stehen da wieder welcherum und verteilen sie FB? stand there again folks around and hand out they flyers? 'Are, again, folks standing around and are they handing out f.?'

Whereas the SLFC in (13a) is conceived of as a single question focusing on the distribution of flyers, the symmetric coordination in (13b) is understood as two basically independent questions asking about two different things.

It is tempting here to blame the overt subject in (13b), for it seems that VP-coordination also shows some kind of one-event interpretation; see the pair of examples in (14), modeled after an example taken from Reis (1993).

(14) a. Jetzt geht er in Buchhandlungen und liest Neuerscheinungen. now goes he in bookstores and reads new publications 'Now, he goes in bookstores and reads new publications'

b. Er geht jetzt in Buchhandlungen und liest Neuerscheinungen. he goes now in bookstores and reads new publications 'Now, he goes in bookstores and reads new publications'

There is one difference though, and this difference is crucial: In the case of SLFC the one-event interpretation is obligatory, whereas it is only optional in the case of VP-coordination. This is - for reasons related to sentence moodbest illustrated with SLFC in a conditional clause. Consider (15).

(15) a.*wenn er Neuerscheinungen liest und geht in Buchhandlungen if he new publications reads and goes in bookstores

b. wenn er Neuerscheinungen liest und in Buchhandlungen geht if he new publications reads and in bookstores goes 
In (15), the conjuncts are switched, which has the effect of blocking a one-event interpretation (since it is a natural course of events to go in a bookstore and read a new publication, but not vice versa). This change in interpretation does not affect symmetric VP-coordination in (15b), but it does affect asymmetric SLFC in (15a), which is clearly marginal, if not ungrammatical.

This shows several things: (i) The one-event interpretation associated with SLFC and AC cannot simply be reduced to whatever mechanism is responsible for one-event interpretations in the case of symmetric VPcoordination. (This seems obvious with AC.) (ii) Since the one-event interpretation in AC and SLFC is obligatory, it is most likely a semantic (and not a pragmatic) property. (iii) Since the other characteristic property of $\mathrm{AC}$ and SLFC - fronting of the finite verb in non-initial conjuncts - is obligatory, too, it seems quite obvious that both properties are in fact two sides of the same coin.

If this is correct, we have to answer the question of how to characterize the fusing semantics of $\mathrm{AC}$ and SLFC, and how this semantics is linked to verb fronting (in AC and SLFC). This is the topic of the following section.

\section{From Discourse to "Odd Coordinations"}

But where to start when trying to characterize the fusing semantics of $\mathrm{AC}$ and SLFC? The fact that AC and SLFC frequently occur with conjunctional adverbs like dann ('then'), dabei ('thereby'), etc., which explicitly refer to coherence relations connecting utterances in discourse, suggests that a somewhat closer look at possible coherence relations may be promising here.

\subsection{Discourse Structure and the "Occasion" Relation}

A more recent classification of coherence relations is found in Kehler (2002). ${ }^{4}$ Kehler (2002), building on work done by David Hume and Jerry Hobbs, subdivides coherence relations into three different classes; see table 1.

\begin{tabular}{ccc}
\hline Resemblance & Cause-Effect & Contiguity \\
\hline Parallel & Result & Occasion \\
Contrast & Explanation & \\
$\ldots$ & $\ldots$ & \\
\hline
\end{tabular}

Table 1: Classification of coherence relations in Kehler (2002)

\footnotetext{
${ }^{4}$ But see Kehler (2002) and this volume for (a discussion of) alternative classifications.
} 
Whereas resemblance relations and cause-effect relations are construed as relations between propositions - structured and unstructured, respectivelycontiguity relations are to be conceived of according to Kehler (2002) as relating events. The class of contiguity relations is in fact a singleton class only consisting of the coherence relation occasion, which is informally characterized as follows: "Occasion can be seen as a mechanism for communicating a complex situation in a multi-utterance discourse by using states of affairs as points of connections between partial descriptions of that situation" (Kehler, 2002, 22). This seems to be exactly what we are looking for. So let's have a closer look at the formal definition. Kehler $(2002,22)$ gives the following characterization of the occasion relation (see also Hobbs, 1990):

occasion (i): Infer a change of state for a system of entities from S1, inferring the final state for this system from S2.

occasion (ii): Infer a change of state for a system of entities from S2, inferring the initial state for this system from S1.

Kehler $(2002,23)$, however, considers this to be only a first approximation to the intuition underlying occasion, since "temporal progression in the absence of a common scenario connecting the events is insufficient in and of itself."

In this respect, I completely agree with Kehler (2002). What we do not agree upon is his classification of coherence relations. The fact that (i) the class of contiguity relations is a singleton, and (ii) the occasion relation relates events rather than propositions suggests that occasion is in fact not a coherence relation in the strict sense, but a discourse phenomenon operating on a different level, interacting with genuine coherence relations. If this is correct, we end up with a much simpler and homogeneous classification of coherence relations; see table 2 .

\begin{tabular}{cc}
\hline Structured Coherence & Unstructured Coherence \\
\hline Parallel & Result \\
Contrast & Explanation \\
$\ldots$ & $\ldots$ \\
\hline
\end{tabular}

Table 2: Coherence relations as relations between (un)structured propositions

This, of course, does not discharge us of specifying exactly what we mean when talking about "occasion". 5 To get a better idea of what "occasion" is all about, consider the following sequence of utterances:

\footnotetext{
5 In the following, the typographical difference between occasion and "occasion" is meant to reflect the aforementioned different theoretical perspectives on the occasion relation.
} 
(16) a. At 6:30 a.m., the lights are turned on in house No. 3.

b. Then, at 6:32 a.m., the lights are turned on in house No. 10 .

c. Then, at 7:01 a.m., the sun comes up.

There are two ways to interpret the sequence of utterances in (16): (i) simply as a sequence of events $e_{1}, e_{2}, e_{3}$, connected by temporal progression, or (ii) as a complex event $e$ - say the 'awakening' of (for example) Downing Street in London- consisting of the subevents $e_{1}, e_{2}, e_{3}$ as perceived of by some person observing the street, and what happens there. What we are interested in is, of course, scenario (ii). Another way to describe what's going on in (16) under scenario (ii) is as follows: The first sentence (16a) sets the scene by describing part of a possibly complex event $e$; the second sentence (16b), speaking about another event $e_{2}$, in a sense 'extends' the description of $e$ by subordinating $e_{2}$ to $e$. This process of 'event subordination' is then reiterated with (16c), resulting in a complex event $e$ consisting of (at least) the events $e_{1}, e_{2}$, and $e_{3}$. We thus can define "occasion" as some kind of event subordination as follows:

\section{(17) OCCASION (EVENT SUBORDINATION)}

Occasion is to be construed as event subordination, i.e., for any two events $e_{1}, e_{2}, \operatorname{OCCASION}\left(e_{1}, e_{2}\right)$ holds iff it is the case that $e_{2} \leq e_{1}$.

Schematically, the situation in (16) can be depicted as follows:

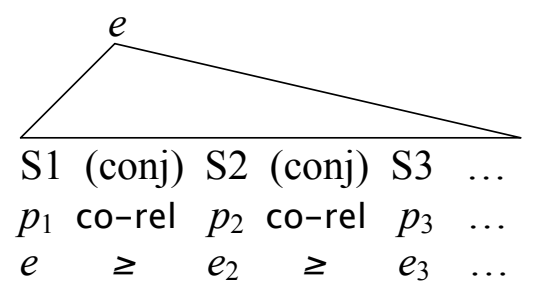

(discourse syntax)

(coherence relations)

(event subordination)

The basic idea is, thus, clear: Sentence S1 introduces an event variable $e$. If the discourse stops here, $e$ denotes the minimal event described by the sentence $\mathrm{S} 1$, i.e., the event $e_{1}$. If, however, an utterance $\mathrm{S} 2$ is added, and $\mathrm{S} 2$ is meant to continue the description of a (complex) event introduced by $\mathrm{S} 1$, then the minimal event $e_{2}$ referred to by $\mathrm{S} 2$ is taken to be a subevent of $e$-which is guaranteed by the condition $e_{2} \leq e$ on $e_{2}$ and $e$. This is, I think, exactly what

\footnotetext{
${ }^{6}$ The term 'event subordination' is reminiscent of the term 'modal subordination,' which is introduced in Roberts (1989). In fact, event subordination and modal subordination do share some important formal characteristics. However, as the following contrast between the modal subordination example in diesem Haus gibt es kein Bad oder es ist gut versteckt ("There is no bathroom in this house or it is well hidden') and the SLFC construction *in diesem Haus gibt es kein Bad oder SL ist gut versteckt shows, modal subordination and event subordination are in principle two independent phenomena; see Reich (2007a) for further discussion.
} 
"occasion" does: While "occasion" ensures that S1 and S2 build a complex structure in the first place, coherence relations like contrast, result, etc. specify the way the propositions denoted by S1 and S2 relate to each other.

As an alternative to event subordination, one could think of (recursively) merging two events $e_{1}$ and $e_{2}$, i.e., we could define a merging operation ' $\oplus$ ' which gives us for every $e_{1}$ and $e_{2}$ a complex event $e=e_{1} \oplus e_{2}$. ${ }^{7}$ The problem with such an approach, however, is that it is all but clear how to define ' $\oplus$ ': What exactly does it mean to merge two events? And given two arbitrary events $e_{1}$ and $e_{2}$, is there always a complex event $e$ which can be considered to be the result of merging $e_{1}$ and $e_{2}$ ? Event subordination avoids such problems in a transparent way: First of all, the subevent relation ' $\leq$ ' is (one of) the most basic relation(s) in any reasonable event mereology; see, e.g., Schein (1993). Second, the subevent relation ' $\leq$ ' can be defined by spatial-temporal inclusion, without losing any of the events' internal structure: This is simply because the event variable $e$ always directly refers to and is conceptualized as an immediately accessible event $e$, without having to build $e$ from other events $e_{1}$ and $e_{2}$.

\subsection{Discourse Structure and Verb Order in German}

So much for the specification of the "occasion" relation in discourse. But how does this relate to AC and SLFC? To see this, consider examples (19) and (20). It is common knowledge that the prototypical verb order of an independently used clause in German is V2 or V1, see (19a,b), whereas the prototypical verb order of dependently used clauses is VE, see (20).

(19) a. Lucky Luke sprang auf sein Pferd Lucky Luke jumped onto his horse

b. Sprang Lucky Luke auf sein Pferd? jumped Lucky Luke onto his horse?

(20) Rantanplan wußte, dass L.L. gleich auf sein Pferd springt. Rantanplan knew, that L.L. PART onto his horse jumps 'Rantanplan knew that L.L. was about to jump onto his horse'

This, of course, is not to say that it is absolutely impossible to use VE-clauses in German independently — as (21) shows this is quite possible:

(21) Dass Lucky Luke ständig auf sein Pferd spring! that Lucky Luke always onto his horse jumps!

\footnotetext{
${ }^{7}$ A merging operation along these lines has been proposed, for example, in Eckhardt (1998).
} 
There are important restrictions on the use of such clauses though: First of all, they never carry the force of an assertion, irrespective of whether they are to be classified as declarative clauses or not. Second, they are so to speak 'islands in discourse,' i.e., they do not directly relate to previous utterances in the usual sense. This suggests that there is an intimate connection between establishing "occasion" (and "occasion"-related coherence relations) on the one hand and word order on the other: Fronting the finite predicate seems to be a necessary - though not necessarily sufficient (see, for example, the case of embedded V2-declaratives in German) — condition on establishing "occasion."

From this point of view, the fact (i) that both AC and SLFC always show fronting of the finite predicate in non-initial conjuncts, and (ii) that this behavior systematically correlates with the presence of some kind of fusing semantics does not look like a coincidence. The question, then, is in what way these processes — one syntactic, the other 'semantic' - relate to each other. Though I'm not (yet) in a position to give a general answer to this question, I do have a concrete proposal concerning the special case of SLFC and AC.

\subsection{The Functional Projection "OccP"}

The crucial idea of the analysis to follow is thus that in AC and SLFC the two conjuncts are in fact systematically linked by the "occasion" relation, which we know well by now from complex structures in discourse. Whereas in discourse, however, the linking of two utterances with the help of "occasion" is optional, and thus most likely pragmatically mediated, this is not the case with AC and SLFC. As we saw above, the fusing semantics of AC and SLFC - now construed as event subordination triggered by "occasion" - is an essential characteristic of these constructions. Therefore, establishing "occasion" in AC and SLFC seems to be a semantic rather than a pragmatic process. ${ }^{8}$ But if it is semantic, there needs to be some syntactic expression or feature that introduces the semantics of "occasion" into the structure of AC and SLFC. Let's call this feature for lack of a better term [OCC], which is obviously short for "occasion." In the following, I will assume that this very feature projects - along with the feature [F] introduced below - a functional projection OccP (more precisely, $\mathrm{OccP} / \mathrm{FP})$. In this sense, "properties typically attributed to coordinate structures in discourse show up in AC and SLFC in 'grammaticalized' form."

Syntax. Before laying out the details of "OccP," however, something needs to be said about the specifics of verb movement and sentence structure in German. In the following, I will assume - following recent work in syntaxthat verb movement in German is triggered by a (strong) syntactic feature [F] that needs to be checked by a finite verb in overt syntax. It is important to see

\footnotetext{
${ }^{8}$ There is no need, however, to assume that coherence relations are established semantically.
} 
here that this feature is neither directly connected to force nor to sentence mood, for there are also - as mentioned above- dependent uses of V1- and V2-sentences in German. I, therefore, take it that $[\mathrm{F}]$ is uninterpretable. ${ }^{9} \mathrm{I}$ furthermore assume that $[\mathrm{F}]$ is the head of a functional projection FP, which distinguishes V1- and V2-sentences from VE-sentences (which are headed by the complementizer projection CP only). A simple sentence like Jan verpetzt Maria ("Jan tells on Mary") is thus analyzed along the lines of (22).

(22) a. Jan verpetzt Maria. ("Jan tells on Maria")

b. $\quad \mathrm{FP}$

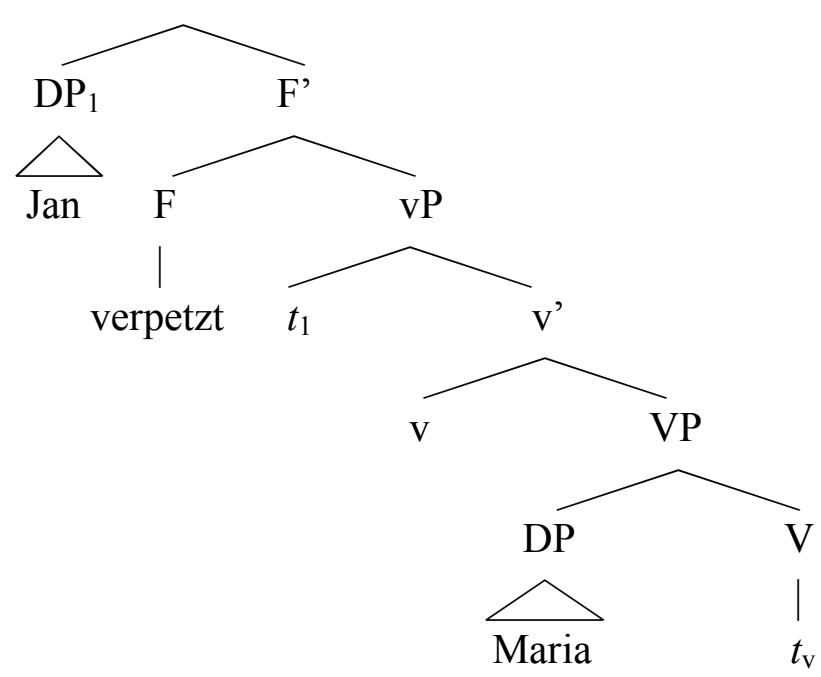

The syntactic structure in (22b) furthermore illustrates that I essentially follow Larson (1988) and others in locating subjects within a functional projection vP, i.e., external to VP. I cannot enter into a discussion on the VP-internal vs. VPexternal hypothesis here for obvious reasons; in what follows, however, it will become apparent why this seems to be the most adequate way of treating subjects - at least from the perspective of AC and SLFC.

After this brief excursion on sentence structure in German, let's come back to the analysis of AC and SLFC. As I have already mentioned several times, one of the crucial characteristics of AC and SLFC is the V1/V2-property of non-initial conjuncts. But what exactly is it that triggers fronting of the finite verb in these cases? As we argued above, this property seems to be intimately connected to the process of establishing "occasion" between two sentences. In other words, it is the feature [OCC], denoting the "occasion" relation, which is to be made responsible for this behavior. In terms of a feature-based syntax, this is

\footnotetext{
${ }^{9}$ But see Truckenbrodt (2006) for a possible interpretation of V2 in German.
} 
- given our assumptions about verb movement- essentially equivalent to saying that the feature $[\mathrm{OCC}]$ selects for the feature $[\mathrm{F}]$; that is, we have (23).

(23) VERB FRONTING IN “AC" AND "SLFC"

[OCC] selects for [F].

If the feature $[\mathrm{OCC}]$ projects a functional projection, and if it furthermore selects for the feature $[\mathrm{F}]$, there are in principle two syntactic configurations where we can expect [OCC] to occur: Either it projects a functional projection of its own, thereby taking FP as its syntactic complement, see (24a), or [OCC] attaches to the head F, and they project a functional projection OccP/FP, see (24b).

(24) a. [OccP Spec [Occ, Occ $[\mathrm{FP}$ Spec $[\mathrm{F}, \mathrm{F}[\ldots$

b. $\quad\left[\mathrm{OccP} / \mathrm{FP}\right.$ Spec $\left[\mathrm{Occ}^{\prime} / \mathrm{F}, \mathrm{Occ} / \mathrm{F}[\ldots\right.$

As far as I can see, there is no compelling independent evidence for the more elaborate structure in (24a). I, therefore, assume that non-initial conjuncts in $\mathrm{AC}$ are assigned the syntactic structure in (24b). If we now reconsider example (10) from section 1.2 above, repeated here as (25) for convenience,

(25) Wenn du nach Hause kommst und der Gerichtsvollzieher if you back home come and the bailiff steht vor der Tür, dann [...]

stands at the door, then [...]

'If you come home, and the b. is standing at the door, then [...]'

we end up with a syntactic analysis along the lines of (26).

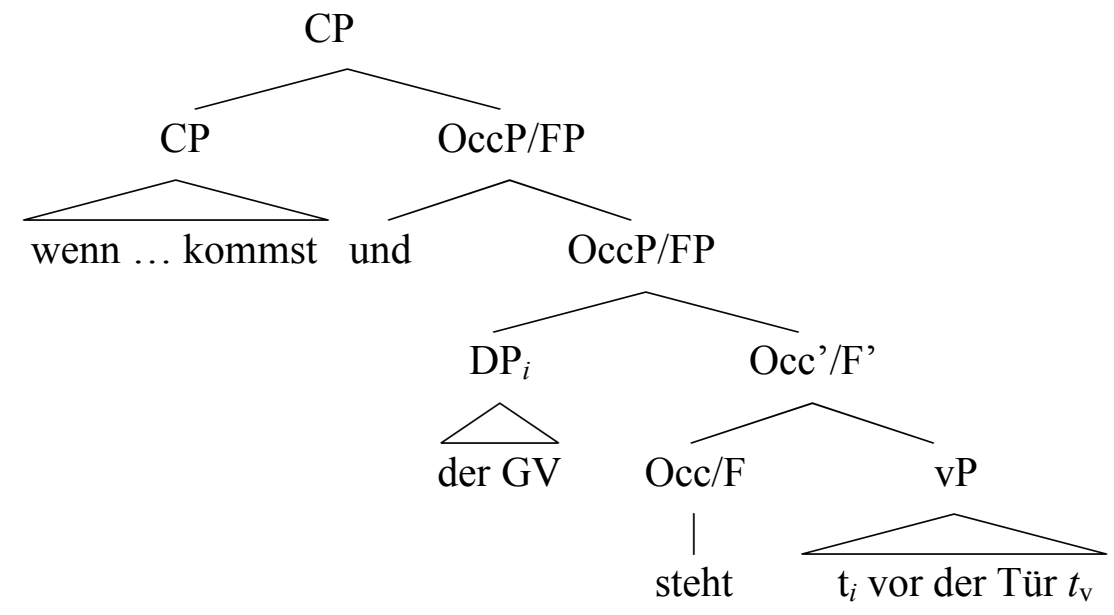


Two comments seem to be in order here. First, whatever the correct analysis of 'standard symmetric coordination' is (see, e.g., Progovac, 1998, Reich, 2007a), the use of und ('and') in AC and SLFC seems to be somewhat different. This is apparent from the fact that 'standard (symmetric) coordination' allows for ATB-movement, while AC and SLFC do not (Höhle, 1983). I, therefore, follow Büring and Hartmann (1998) in analyzing coordination as adjunction in the case of SLFC (and AC). As we will see in a moment, this assumption is in fact an immediate consequence of the semantics of [OCC].

The other comment concerns the adjunction site of OccP/FP. In the case of dependent uses of AC and SLFC as in (25/26), OccP/FP seems to (have a strong tendency to) adjoin sentence-externally, i.e., to adjoin to the whole CP. Even though this is somewhat unexpected from a semantic point of view, there is good evidence from the binding of pronouns (quantifiers in the first conjunct do not easily bind pronouns in the second conjunct) and scope of negation (the scope of negation is restricted to the conjunct it is part of) that this is in fact correct; see Reich $(2007 \mathrm{a}, \mathrm{b})$. Here, I just want to touch on this matter by illustrating the behavior of negation in this respect. Consider (27).

(27) \#Wenn du nicht die Kronjuwelen klaust und (du) wirst if you not the crown jewels steal and (you) get dabei erwischt, dann hast du Glück gehabt thereby caught, then have you luck had

From a pragmatic point of view, the only reading that makes sense here is the one with wide scope of negation: If it is not the case [that you steal the crown jewels and you get caught red-handed], then you are lucky. But as a matter of fact, this reading is not available in (27). The only reading available is the selfcontradictory one with scope of negation restricted to the first conjunct: If [it is not the case that you steal the crown jewels] and you get caught red-handed, then you are lucky. This is consistent with the assumption that the second conjunct attaches to CP. Because of space limitations, I cannot go into details here, but the reader is referred to Reich $(2007 \mathrm{a}, \mathrm{b})$ for further discussion, including possible implications for the semantics of conditionals.

Semantics. Having introduced the main syntactic properties of [OCC], let's have a closer look at its semantics. We already argued in some detail that [OCC] denotes the "occasion" relation, i.e., that it implements event subordination. If we want to spell out this idea in a formal setup, we need to assume - in accordance with the literature on lexical semantics and 'Aktionsarten' in the tradition of Donald Davidson - that each verb introduces an event variable $e$, i.e., that sentences are taken to denote sets of (possible) events. Given these assumptions, we can specify the semantics of [OCC] as given in (28). 


\section{(28) SEMANTICS OF [OCC] \\ $\llbracket[\mathrm{OCC}] \rrbracket=\lambda Q \lambda \Im \lambda P \lambda e \exists e_{2}\left[\Im\left(Q\left(e_{2}\right)\right)(P(e)) \& e_{2} \leq e\right]$}

According to (28), the feature [OCC] implements two conditions: (i) The second conjunct $Q$ is conjoined with the first conjunct $P$ by some appropriate coordinating conjunction $\mathfrak{I}$; this relates to the condition $\mathfrak{I}\left(Q\left(e_{2}\right)\right)(P(e))$, which can be rewritten as " $P(e) \& Q\left(e_{2}\right)$ ", if $\mathfrak{\Im}$ is instantiated by and. (ii) The feature [OCC] furthermore states that the event $e_{2}$ corresponding to the second conjunct $Q$ is a subevent of the event $e$ introduced by the first conjunct $P$. While condition (i) prevents the coordinating conjunction $\mathfrak{I}$ from projecting its own functional projection (otherwise we run into a type mismatch), and thus is to be made responsible for the adjunction structure of $\mathrm{AC}$ and SLFC, condition (ii) implements the by now familiar event subordination " $e_{2} \leq e$ ".

If we take (essentially following Kratzer, 1991) the complementizer wenn ('if') to be semantically empty, it is straightforward to see that the proposed semantics derives the interpretation given in (29) for the $\mathrm{AC}$ in (26), where $\mathrm{CBH}$ stands for the complex predicate "come back home," and SAD is shorthand for the other complex predicate "stands at the door."

$$
\lambda e \exists e_{2}\left[\left[C B H(e, y o u) \&\left(S A D\left(e_{2}, \text { bailiff }\right)\right] \& e_{2} \leq e\right]\right.
$$

According to (29), the AC in (26) denotes that set of (complex) events $e$ which are directly characterized as 'you are coming back home' events - because of the condition $C B H(e, y o u)$ - and indirectly as being at the same time also 'the bailiff is standing at the door' events - because of the condition $\operatorname{SAD}\left(e_{2}\right.$, bailiff $)$ mediated by event subordination $e_{2} \leq e$. This seems to be a good and reasonable approximation to the fusing semantics of AC and SLFC.

The "Vorfeld" of Non-initial Conjuncts in AC. Before switching over to SLFC let me point out an interesting prediction of this approach that concerns overt realizations of the prefield of non-initial conjuncts in AC. Following Frey (2004), I assume that the German prefield can be filled in three different ways: (i) by base generation (of some specific elements, e.g., the prefield-es), (ii) by formal movement (FM), and (iii) by real A-bar-movement. Whereas real A-barmovement is semantically motivated by some interpretable feature in the left periphery ([TOPIC], [CONTRAST], [WH], etc.) and may, in principle, start from any position within the middle field, FM is not triggered semantically (it is just 'formal'), and it is restricted to short movement of the leftmost expression in the middle field (which is quite often, but not always the subject).

Now, what about the prefield of non-initial conjuncts in AC? As we saw above, the prefield is, in this case, not simply the specifier position of some FP, but the specifier position of an OccP/FP; and since the feature [OCC] is 
interpretable, we expect movement to $[\mathrm{Spec}, \mathrm{OccP} / \mathrm{FP}]$ to be restricted as follows: While base generation and FM to [Spec,OccP/FP] should be fine (see, e.g., (30)), semantically motivated movement should be out if (and only if) the semantics of the triggering feature is incompatible with the semantics of [OCC]. This definitely excludes $w h$-movement to this position; but it also prevents real A-bar-movement of a (lower ranked) object, which - according to Frey (2004) - always involves some kind of contrastive interpretation; see (31).

(30) Wenn du nach Hause kommst und dir ist schlecht if you back home come and you[DAT] feel sick

*Wenn du nach Hause kommst und mit deiner Frau
if you back home come and with your wife
spricht der Gerichtsvollzieher, dann ...
speaks the bailiff,

There is far more to say about this intricate topic; alas, I have to refer the reader once more to Reich (2007a) for more detailed discussion.

\subsection{Subject Gaps in Coordinate Structures}

As I argued in section 1, it seems safe to assume that AC and SLFC are - apart from some minor differences - essentially one and the same phenomenon. Or to put it another way: SLFC is basically AC with a subject gap.

If this is correct, we have to answer at least two questions: (i) Why is it that in AC subjects (and only subjects) can be dropped, resulting in an SLFC? (ii) What is the nature of the subject gap —is it just an instance of some wellknown kind of ellipsis or is it due to something special?

As we saw in the introduction, there seems to be no (straightforward) way to derive the gap from ATB-movement or forward deletion. Moreover, the fact that subject gaps (as the name suggests) are restricted to subjects - a restriction which is, to say the least, not very widespread in ellipsis phenomena- suggests that the second option, i.e., that the subject gap is something special, is true. The fact that subject gaps in coordinate structures are limited to AC further suggests that they are closely tied to some idiosyncratic property shared by these constructions. The hypothesis I want to pursue in the following is that this very property is the 'fusing semantics' of AC and SLFC, i.e., it is event subordination, implemented with the help of [OCC], that licenses dropping the subject. The crucial idea of the approach to follow is thus that subject gaps are possible in AC (and only in AC), since event subordination enables us to semantically reconstruct the subject of the second conjunct from the subject of the first conjunct. This will follow from the 'subject condition.' 
Syntax and Semantics of $v P$. Before I am in a position to precisely state the 'subject condition,' however, I have to introduce some more assumptions about the syntax and semantics of sentence structure in German. In the previous section, I made the assumption that subjects - understood as nominative DPs that constitute the highest thematic argument - are to be located VP-externally in a functional projection called vP. Since there are verbs in German that do not allow for subjects in this strict sense (see, e.g., mir[DAT] ist komisch zumute 'I'm in a funny mood'), this means that vP does not project independently, but is triggered by a (non-interpretable) feature [v] on the relevant verbs.

In this section, I propose - borrowing ideas from Kratzer (1996) - that the externality of subjects is not restricted to syntax, but extends to semantics. Let me illustrate this with the following example. In (32a) the subject der Gerichtsvollzieher is severed from the verbs' semantic representation, and the VP vor der Tür steht ('stands at the door') already denotes an (almost) saturated semantic object of the type 'set of events,' namely the set of events that are 'stands at the door'-events. The head [v] itself is semantically vacuous, see (32b), but it carries (by assumption) a feature [SUBJ] which is interpretable, and which states that the specifier of $\mathrm{vP}$ is a subject (to $e$ ), see $(32 \mathrm{c}){ }^{10}$ this statement is then conjoined with the denotation of its complement, see (32d).

(32) a.

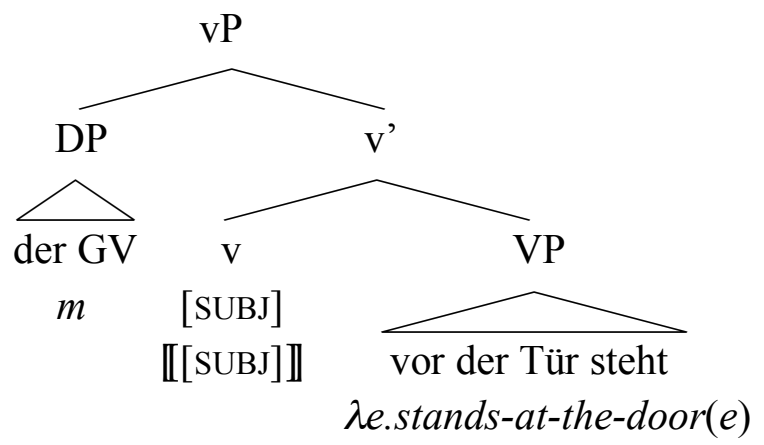

b. $\quad \llbracket \mathrm{v} \rrbracket=\lambda Q \cdot Q$

c. $\quad \llbracket[\mathrm{SUBJ}] \rrbracket=\lambda Q \lambda x \lambda e[\operatorname{subj}(e)(x) \& Q(e)]$

d. $\llbracket(32 \mathrm{a}) \rrbracket=\lambda e[\operatorname{subj}(e)(m) \&$ stands-at-the-door $(e)]$

The vP as a whole thus denotes the set of events $e$ such that $e$ is a 'stands at the door'-event, and the bailiff is the subject in $e$ (i.e., he realizes the highest thematic role in the 'stands at the door'-event $e$ ). This seems correct.

Two notes: First, as a consequence of severing the external argument from its verb, both VP and vP are now of the same semantic type, i.e., they both

\footnotetext{
${ }^{10}$ The property of being a subject relative to a given event $e$ needs to be independently defined, of course. Roughly speaking, $x$ is a subject to an event $e-$ i.e., $\llbracket \operatorname{subj}(e)(x) \rrbracket=1-$ iff $x$ refers to the highest thematic role participating in the event $e$; see Reich (2007a) for details.
} 
denote sets of events. Second, weather verbs like regnen ('rain') do not select for a thematic argument, but for an expletive subject es ('it'). In such cases [v] does not carry the feature $[\mathrm{SUBJ}]$, i.e., the $\mathrm{vP}$ contributes nothing to semantic interpretation; [v] just assigns nominative case to the expletive es.

The Subject Condition. Let's consider now an AC with an overt subject in its second conjunct which is coreferential with the subject in the first conjunct; see (33). Its semantic representation is given in (34).

(33) Wenn du nach Hause kommst und du siehst den if you back home come and you see the Gerichtsvollzieher vor der Tür, dann [...] bailiff at the door, then [...]

(34) $\lambda e \exists e_{2}[\operatorname{subj}(e)($ you $) \&$ come-back-home $(e)$ $\operatorname{subj}\left(e_{2}\right)(y o u) \&$ see-at-the-door $\left(e_{2}\right)$ (bailiff $\left.) \& e_{2} \leq e\right]$

The semantic representation in (34), of course, contains two characterizations of the subject you, namely 'subj(e)(you)' and 'subj( $\left.e_{2}\right)(y o u)$ '. Since we know that we can drop you in the second conjunct, what we'd like to be able to say is that the second characterization is in some sense redundant - for if it were, then the subject in the second conjunct could be semantically reconstructed on the basis of the subject in the first conjunct, and the gap would be licensed.

However, since the event variables $e$ and $e_{2}$ do not necessarily refer to the same event, 'subj(e)(you)' does not entail 'subj( $\left.e_{2}\right)(y o u)$ ' nor vice versa. But wait: Since one of the crucial characteristics of AC is that AC systematically triggers event subordination ' $e_{2} \leq e$ ', it could very well be that this property of $\mathrm{AC}$ is the right piece of information that bridges the gap and licenses the entailment; that is, the question to ask is the following: Is it possible to conclude from the fact that you is the subject of $e$ and the fact that $e_{2}$ is a subevent of $e$ that you is also the subject of $e_{2}$ ? Again, the answer is "no." If the answer were "yes," then it would be impossible to have an AC with an overt, non-coreferent subject in the second conjunct. But, as (25) shows, this is possible.

So it seems that we're stuck. But in fact we are not. What I just showed is that the conditions ' $\operatorname{subj}(e)(y o u)$ ' and ' $e_{2} \leq e$ ' do not strictly [!] entail -in the sense of a material conditional- the condition ' $\operatorname{subj}\left(e_{2}\right)(y o u)$ '. It is well known, however, that entailments in natural language typically are not strict, but nonmonotonic (see, e.g., Asher \& Lascarides, 2003). To see this, consider (35).

(35) a. If John comes, the party will be a success.

b. If John and Mary come, the party will be a success. 
If entailments in natural language adhered to the material conditional, it should be possible to conclude from the truth of (35a) the truth of (35b), since it follows from ' $p_{1} \rightarrow q$ ' that ' $p_{1} \& p_{2} \rightarrow q$ ' for any proposition $p_{2}$. But in fact we cannot strictly conclude from (35a) that (35b) is true as well -it may very well be that John behaves completely different in the presence of Mary.

So let's assume that the entailment we are after is in fact a non-monotonic entailment (symbolic: '»'), i.e., that the 'subject condition' in (36) holds.

(36) SUBJECT CONDITION

For any two events $e, e_{2}$ and any individual $x$ the following holds:

$$
\operatorname{subj}(e)(x) \& e_{2} \leq e \gg \operatorname{subj}\left(e_{2}\right)(x)
$$

What (36) tells us is that -in the absence of any other information - we can conclude from the fact that $x$ is the subject of $e$, and that $e_{2}$ is a subevent of $e$, that $x$ is also the subject of $e_{2}$. If we assume the validity of (36), then a dropped subject can be semantically reconstructed from its antecedent - and this seems to be (almost) all that is needed for licensing a subject gap in the second conjunct of an AC. Note, by the way, that (36) does not license subject gaps in initial conjuncts, for event subordination is an asymmetric relation.

That the assumption of (36) is in fact consistent is easily shown, for there are only three cases to consider. Either the subject of the second conjunct is realized, or it isn't. If it is, then it is either coreferent, or it is not. Suppose we have a non-coreferent overt subject, then the conditions ' $\operatorname{subj}\left(e_{2}\right)(y)$ ' and ' $x \neq y$ ' are added to the antecedent of (36); in this scenario the conclusion is blocked, since the added conditions in the antecedent contradict the conclusion. Suppose, alternatively, that we have an overt, coreferent subject, then the condition ' $\operatorname{subj}\left(e_{2}\right)(x)$ ' is added, and the entailment is trivialized. The last scenario is the one with a covert coreferent subject, i.e., the scenario stated in (36).

Subject Gaps and Properties of $v P$. That there are in fact only three scenarios to consider follows from the syntax of subject gaps: What I do have to assume - and what I will, henceforth, assume - is that to drop the subject in an $\mathrm{AC}$ means to drop the feature $[\mathrm{SUBJ}]$; see (37).

\section{(37) SUBJECT GAPS (PART I)}

In an SLFC the head [v] of the second conjunct lacks [SUBJ].

As we saw above, dropping the feature [SUBJ] is equivalent to saying that no condition of the form ' $\operatorname{subj}\left(e_{2}\right)(x)$ ' is introduced in the relevant conjunct, i.e., from the point of view of syntax no thematic subject is realized. In this respect, the situation in SLFC seems to be — at least to some extent - comparable to the 
one with weather verbs like regnen ('rain'). There is one important difference, though: Whereas in the case of weather verbs there simply is no highest thematic role in the event structure of $e$ (the 'raining event') that could be realized in syntax, the event structure corresponding to the relevant SLFC conjunct does of course include a highest thematic role, which is in need of syntactic realization; nevertheless, the syntactic realization of this argument can be suppressed in SLFC, for we are - thanks to the 'subject condition' - able to link the not realized thematic role of the second conjunct to the subject of the first one. In this sense, a coreferent subject in the second conjunct of an AC is redundant, and its dropping is 'parasitic' on the semantics of AC.

What we have not yet talked about is the nature of the gap itself. As it turns out, the nature of the gap is already completely determined by the assumptions we made above. It is clear from what has been said that the subject gap is to be located in the specifier position [Spec,vP] of vP. This position, however, cannot be completely empty, since the task of the head [v] is to assign nominative to some element in $[\mathrm{Spec}, \mathrm{vP}]$, and there is no good reason to assume that this is somehow suppressed in SLFC. Since the head [v] is not accompanied by the feature [SUBJ], the element in [Spec,vP] needs to be some kind of expletive (if it were referential, it would have to be conjoined with the verbs' interpretation, but there is no way to conjoin an expression of type $e$ with an expression of type $t$ without the mediating semantics of the feature [SUBJ]). The only expression fulfilling all these criteria we know of seems to be the expletive subject es. So, is the subject gap a covert variant of es? Most certainly not, since es carries in addition to the feature nominative the features 3rd person singular; the finite verb in the second conjunct of an SLFC, however, is not restricted to 3rd person singular, but seems to agree in person and number with the subject in the first conjunct. ${ }^{11}$ It follows thus that the subject gap is unspecified with respect to person and number. To sum up, what we know about the nature of the gap is the following: It is covert, it is an expletive, and it is unspecified with respect to person and number, but it is specified with respect to case - it carries the case nominative. The only expression I know of that has exactly these properties is the feature [NOM] itself. So let's assume the following restriction:

(38) SUBJECT GAPS (PART II)

In an SLFC [Spec,vP] of the second conjunct is filled by [NOM].

\footnotetext{
11 This is, of course, a tough nut to crack in approaches like the one proposed in this paper. There are, as far as I can see, at least two promising ways to tackle the problem: Either there is some syntactic process like 'long distance agreement' available (see, e.g., Sternefeld 2006b, chap. V.3) or person and number agreement is semantically mediated (see, e.g., Reich 2007a).
} 
In fact, (38) is exactly what we expect in a feature-driven syntax, where each feature $[\mathrm{x}]$ has to be matched with its counterpart to avoid a crashing derivation: The only task of the head $[\mathrm{v}]$ is to match its feature [NOM] with a feature [NOM] in $[\mathrm{Spec}, \mathrm{vP}]$ (i.e., it 'assigns nominative' to [Spec,vP]); since there are no other processes going on within $\mathrm{vP}$ in the case of SLFC, there is no need (and it is even impossible) to realize another feature than $[\mathrm{NOM}]$ in $[\mathrm{Spec}, \mathrm{vP}]$.

Subject Gaps and the V1-Property of Non-initial Conjuncts. There is one last question we need to answer: Why is it that dropping the subject in an AC systematically results in a V1-structure (rather than a 'gapped' V2-structure)? Or to put it differently: Why does a subject gap block movement to and base generation in the prefield of a V2-clause?

First note that the subject gap [NOM] is a covert expression which has to be - according to, e.g., Lobeck (1995) - (i) licensed, and (ii) identified. There are two configurations in which covert expressions are licensed: either in a complement relation, or in a spec-head configuration. Since the subject gap is not in a complement, but a specifier position, licensing needs to take place in a spec-head configuration. The phenomenon of 'Topic Drop' in German tells us that licensing covert expressions in such a configuration is in fact possible in German. Essentially following Fries (1988), the syntax of Topic Drop can be sketched as follows: Dropping the topic is (i) licensed by the matching feature [TOPIC] in the head [F], and it is identified by the finite verb in [F]; see (39).

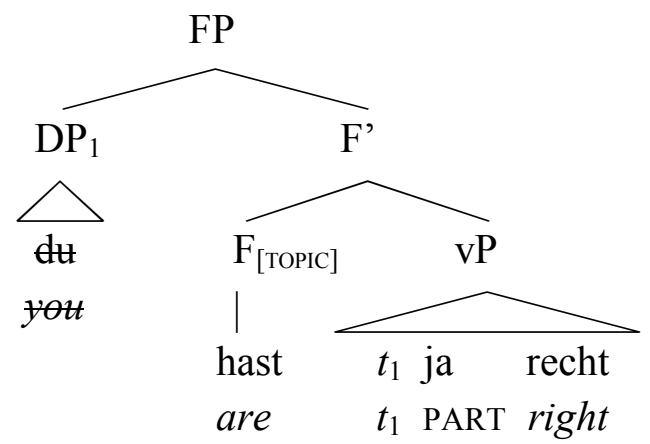

Now consider Wunderlich's (1988) example (40) of a typical root clause SLFC.

(40) In den Wald ging der Jäger und schoss einen Hasen in the forest went the hunter and shot a rabbit

What we are primarily interested in is, of course, the syntactic structure of the second conjunct. If the licensing of the subject gap in examples like (40) is in fact essentially structurally parallel to the licensing of Topic Drop, then there needs to be some interpretable feature corresponding to [TOPIC] that is located 
in the head [v] of vP; the obvious candidate here is of course the feature [OCC], the core characteristic of $\mathrm{AC}$, which denotes event subordination, and thus feeds the licensing 'subject condition' in (36).

The fact that the subject gap is identified by the fronted finite verb then follows immediately from the syntax of the feature [OCC]: Since [OCC] selects for the feature $[\mathrm{F}]$, and $[\mathrm{OCC}]$ is to be located in the head $[\mathrm{v}]$ of $\mathrm{vP}$ (the subject gap in $[\mathrm{Spec}, \mathrm{vP}]$ is licensed in a spec-head configuration), it follows that $[\mathrm{F}]$ is to be located in the head [v] of $\mathrm{vP}$, too. In other words: Whereas an $\mathrm{AC}$ with an overt subject is a projection of OccP/FP (see the previous section), an SLFC is an even more 'compressed' projection $\mathrm{OccP} / \mathrm{FP} / \mathrm{vP}$; see the syntactic structure given in (41), and its semantic interpretation in (42).

(41) $\left[\mathrm{FP}\right.$ In den Wald [F, ging ${ }_{i}$ [vP der Jäger $\left[\mathrm{v}, t_{i,[\mathrm{SuB}]}\right]$

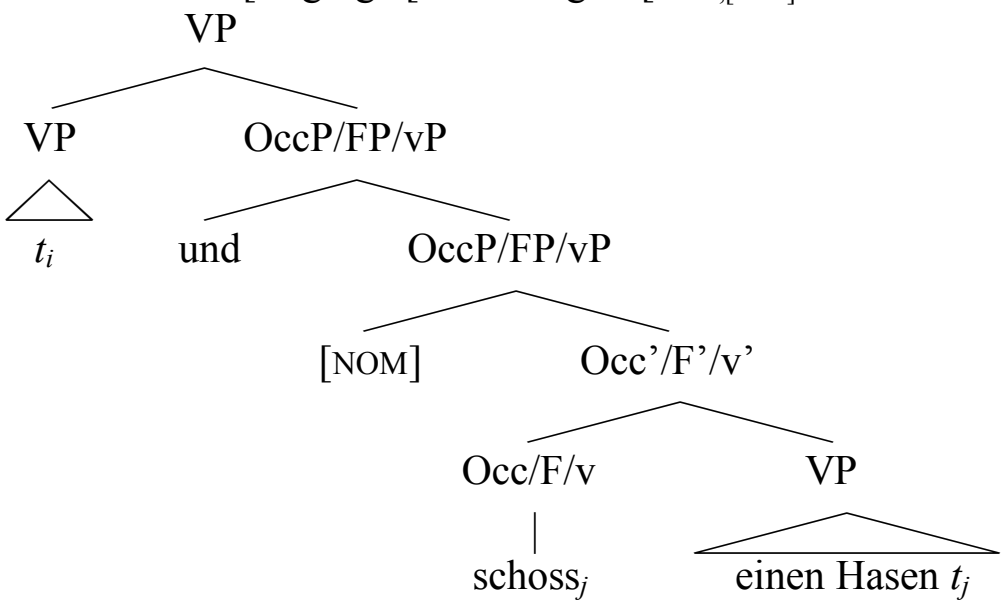

(42) $\lambda e \exists e_{2}[\operatorname{subj}(e)$ (the-hunter) \&

[went-in-the-forest $(e) \& \operatorname{shot}\left(e_{2}\right)(a$-rabbit $\left.\left.)\right] \& e_{2} \leq e\right]$

In (41) the subject gap [NOM] is (i) licensed by the interpretable feature [OCC], and (ii) identified by the overt fronted finite verb schoss ('shot'). Since the prefield of the fronted structure in (41) is identical with the specifier position of $\mathrm{OccP} / \mathrm{FP} / \mathrm{vP}$, and this position is already (and necessarily) filled with the case feature [NOM] (required by the head [v] of $\mathrm{vP}$ ), movement to this position as well as base generation of some other element in this position is blocked.

On Where to Attach the Second Conjunct of an AC. If we compare the analysis of the root SLFC in (41) with the analysis of the dependent AC in (26), we observe another, somewhat surprising difference: Whereas in (26) the second conjunct is adjoined sentence-externally, i.e., to CP, it is adjoined sentence-internally in (41). This corresponds to the empirical observation that 
in cases like (26) negation cannot (easily) have scope over the second conjunct of an AC, but in cases like (43), taken from Höhle (1983), it can.

(43) Hoffentlich sieht er uns nicht und zeigt uns an! hopefully sees he us not and reports us PART!

A closer look at the facts reveals that the empirical generalization seems to be as follows: If the finite verb in the initial conjunct is fronted (V1/V2), then there is a strong tendency to attach the second conjunct sentence-internally, i.e., to $\mathrm{VP}$; if it is not (VE in the first conjunct), then there is a strong tendency to attach the second conjunct sentence-externally, i.e., to CP. This is, however, not a strict rule, for there are obvious - but nevertheless systematic- exceptions to this generalization (see Reich, 2007a, for further discussion).

\section{Summary}

Starting from semantic and pragmatic considerations, I have proposed an analysis of Asymmetric Coordination (AC) and SLF-Coordination (SLFC) that ties together their semantic and syntactic characteristics by considering them an immediate consequence of the fact that in AC and SLFC properties typically attributed to coordinate structures in discourse show up in 'grammaticalized' form. Concretely, I have suggested that in AC and SLFC both conjuncts are linked by the "occasion" relation, which I have furthermore argued to express 'event subordination.' In a feature-based syntax this has been implemented with the help of a syntactic feature [OCC] that selects for the feature [F], which is, in turn, responsible for the fronting of the finite verb in non-initial conjuncts.

Finally, the dropping of the subject in the case of SLFC has been argued to be in a sense 'parasitic' on the special 'fusing' semantics of SLFC: Given event subordination, a coreferent subject in the second conjunct of an $\mathrm{AC}$ is redundant in the sense that it can be reconstructed with the help of a nonmonotonic inference - the 'subject condition' - from the semantics of the first conjunct. On the syntactic side, the gap has been construed as the case feature [NOM], which — being a covert expression — has to be licensed (paralleling Topic Drop in German) by the "occasion" feature [OCC] in a spec/headconfiguration and identified by the fronted finite verb. The fact that the prefield -i.e., Spec of OccP/FP/vP - is filled with the feature [NOM] derives the V1property of non-initial conjuncts in SLFC.

\section{References}


Asher, Nicholas and Alex Lascarides. 2003. Logics of conversation. Cambridge: Cambridge University Press.

Büring, Daniel and Katharina Hartmann. 1998. Asymmetrische Koordination. Linguistische Berichte 174, 172-201.

Eckhardt, Regine. 1998. Adverbs, events, and other things. Tübingen: Niemeyer.

Fortmann, Christian. 2005. Die Lücken im Bild von der SubjektlückenKonstruktion. Linguistische Berichte 204, 441-476.

Frank, Annette. 2002. A (discourse) functional analysis of asymmetric coordination. In Proceedings of the LFG02 Conference, M. Butt and T. King (eds.), 174-196.

Frey, Werner. 2004. The grammar-pragmatics interface and the German prefield. Sprache \& Pragmatik 52, 1-39.

Fries, Norbert. 1988. Über das Nulltopik im Deutschen. Sprache \& Pragmatik 3, 19-49.

Hartmann, Katharina. 2002. Right Node Raising and Gapping: Interface conditions on prosodic deletion. Philadelphia, Amsterdam: Benjamins.

Heycock, Caroline and Anthony Kroch. 1994. Verb movement and coordination in a dynamic theory of licensing. The Linguistic Review 11, 257-284.

Hobbs, Jerry R. 1990. Literature and Cognition. Stanford: CSLI.

Höhle, Tilman N. 1983. Subjektlücken in Koordinationen. Ms., Tübingen.

Höhle, Tilman N. 1986. Der Begriff 'Mittelfeld'. Anmerkungen über die Theorie der topologischen Felder. In Textlinguistik contra Stilistik. Akten des VII. Internationalen Germanisten-Kongresses Göttingen 1985, Bd. 3, W. E. Weiss, H. E. Wiegand, and M. Reis (eds.), 329-340. Tübingen: Niemeyer.

Höhle, Tilman N. 1990. Assumptions about asymmetric coordination in German. In Grammar in Progress: Glow Essays for Henk van Riemsdijk, J. Mascaró and M. Nespor (eds.), 221-235. Dordrecht: Foris.

Höhle, Tilman N. 1991. On reconstruction and coordination. In Representation and Derivation in the Theory of Grammar, H. Haider and K. Netter (eds.), 139-197. Dordrecht: Kluwer.

Kehler, Andrew. 2002. Coherence, reference, and the theory of grammar. Stanford, California: CSLI.

Kratzer, Angelika. 1991. Conditionals. In Semantics: An International Handbook of Contemporary Research, A. von Stechow and D. Wunderlich (eds.), 651-656. Berlin: De Gruyter.

Kratzer, Angelika. 1996. Severing the external argument from its verb. In Phrase Structure and the Lexicon, J. Rooryck and L. Zaring (eds.), 109137. Dordrecht: Kluwer Academic Publishers.

Larson, Richard. 1988. On the double object construction. Linguistic Inquiry 19, 335-391. 
Lobeck, Anne. 1995. Ellipsis. Functional heads: Licensing, and identification. New York, Oxford: Oxford University Press.

Oirsouw, Robert van. 1993. Coordination. In Syntax: An International Handbook of Contemporary Research, J. Jacobs, A. von Stechow, W. Sternefeld, and T. Vennemann (eds.), 748-763. Berlin, New York: De Gruyter.

Progovac, Ljiljana. 1998. Structure for coordination I/II. Glot International 3, $3-6 / 9$.

Reich, Ingo. 2007a. Asymmetrische Koordination im Deutschen. Habilitationsschrift, Universität Tübingen.

Reich, Ingo. 2007b. What asymmetric coordination in German tells us about the syntax and semantics of conditionals. In Proceedings of Sinn \& Bedeutung 11, Barcelona. Universitat Pompeu Fabra.

Reis, Marga. 1993. Satzfügung und kommunikative Gewichtung: Zur Grammatik und Pragmatik von Neben- vs. Unterordnung am Beispiel 'implikativer' und-Konstruktionen im Deutschen. In Wortstellung und Informationsstruktur, M. Reis (ed.), 203-249. Tübingen: Niemeyer.

Roberts, Craige. 1989. Modal subordination and pronominal anaphora in discourse. Linguistics and Philosophy 12, 683-721.

Schein, Barry. 1993. Plurals and events. Cambridge, Mass.: MIT Press.

Sternefeld, Wolfgang. 2006a. Syntax. Eine morphologisch motivierte generative Beschreibung des Deutschen. Band 1. Tübingen: Stauffenburg.

Sternefeld, Wolfgang. 2006b. Syntax. Eine morphologisch motivierte generative Beschreibung des Deutschen. Band 2. Tübingen: Stauffenburg.

Te Velde, John R. 2006. Deriving coordinate symmetries: A phase-based approach integrating Select, Merge, Copy and Match. Philadelphia, Amsterdam: Benjamins.

Truckenbrodt, Hubert. 2006. On the semantic motivation of syntactic verb movement to C. Theoretical Linguistics 32, 257-306.

Wilder, Chris. 1997. Some properties of ellipsis in coordination. In Studies on Universal Grammar and Typological Variation, A. Alexiadou and T. A. Hall (eds.), 59-107. Philadelphia, Amsterdam: Benjamins.

Williams, Edwin. 1978. Across the board rule application. Linguistic Inquiry 9, 31-43.

Wunderlich, Dieter. 1988. Some problems of coordination in German. In Natural Language Parsing and Linguistic Theories, U. Reyle and C. Rohrer (eds.), 289-316. Dordrecht: Reidel. 